\title{
Adriano Marchetti, Prédilections. Incursions en Belgique
}

\section{Florence Martineau}

\section{Q OpenEdition}

10 Journals

\section{Édition électronique}

URL : https://journals.openedition.org/studifrancesi/41227

DOI : 10.4000/studifrancesi.41227

ISSN : 2421-5856

Éditeur

Rosenberg \& Sellier

\section{Édition imprimée}

Date de publication : 1 juillet 2004

Pagination : 222-223

ISSN : 0039-2944

\section{Référence électronique}

Florence Martineau, « Adriano Marchetti, Prédilections. Incursions en Belgique », Studi Francesi [En ligne], 142 (XLVIII | I) | 2004, mis en ligne le 30 novembre 2015, consulté le 09 septembre 2021. URL : http:// journals.openedition.org/studifrancesi/41227 ; DOI : https://doi.org/10.4000/studifrancesi.41227

Ce document a été généré automatiquement le 9 septembre 2021.

\section{(c) (i) (9)}

Studi Francesi è distribuita con Licenza Creative Commons Attribuzione - Non commerciale - Non opere derivate 4.0 Internazionale. 


\title{
Adriano Marchetti, Prédilections. Incursions en Belgique
}

\author{
Florence Martineau
}

\section{RÉFÉRENCE}

ADRIANO MARCHETTI, Prédilections. Incursions en Belgique, Rimini, Panozzo, 2002, pp. 188.

1 La double modestie du titre et du sous-titre de ce livre ne doit pas tromper. Certes, il s'agit de prédilections, où l'on entendra bien le choix affiché d'un critique qui prend ses risques en première personne; certes encore, il s'agit d'incursions en Belgique, terme par lequel l'auteur avoue ses promenades solitaires qu'il présente comme des essais, des tentatives, des opérations de reconnaissance.

2 Adriano MARCHETTI a rassemblé dans cet ouvrage quelques-unes de ses «prédilections» (il en est d'autres) par le lieu d'origine des auteurs qu'il nous invite à approfondir et, parfois, à découvrir: la Belgique. Mais s'ils ont en commun d'être nés belges, ces écrivains ont pour véritable patrie la langue française et, s'ils ont suscité la réflexion de l'essayiste, c'est qu'ils faisaient écho en quelque manière à ses propres préoccupations concernant la création poétique et le langage. C'est donc le questionnement de l'A. qui unit les œuvres et leurs auteurs plutôt que le hasard de leur naissance. Toutefois, les différents écrivains (ils sont bien différents, en effet) sont examinés dans leur singularité ; leur thématique particulière et leur écriture unique sont mises en évidence par un critique qui plie son intelligence aux contours originaux de leur invention.

3 Les six chapitres qui constituent le volume suggèrent une triple composition: il s'agit d'abord de six figures de la littérature belge, classés par ordre chronologique, de Charles de Coster à Henry Bauchau. Il s'agit ensuite d'une enquête serrée sur les formes de l'écriture: la légende, la chanson, le théâtre, le poème, le roman, mais aussi le texte philosophique avec Max Loreau. Il s'agit enfin d'une méditation en étroite connivence avec des textes qui, chacun à leur manière - de façon plus ou moins délibérée, plus ou moins aiguë - interrogent le mystère de l'écriture, mystère qui plonge ses racines dans 
celui de la parole: la littérature s'accomplit entre la légende et le mythe selon un fil rouge secrètement distribué dans le live.

4 Si les titres de ces chapitres sont doubles, c'est à chaque fois pour inventer une nouvelle tension: entre les deux grands figures du temps (Chronos et Kairos), entre deux régimes du spectacle (Parade et mascarade), entre deux cordes enfin. Héraclite est bien présent dans L'Arc et la Lyre - il est cité aussi dans l'épigraphe du chapitre consacré à Christophe Colomb de M. de Ghelderode dans celle du chapitre consacré à Loreau et dans la lecture profonde de la poésie de S. Lilar. Trois figures de la parole sont alors évoquées: le murmure de l'ange avec $\mathrm{Ch}$. Van Lerberghe, la voix du commencement avec $M$. Loreau, le labyrinthe des mots avec $\mathrm{H}$. Bauchau. Si MARCHETTI privilégie l'éclairage philosophique, c'est parce que la littérature lui offre l'occasion d'une méditation sur la forme et sur le temps, sur la genèse et sur le devenir. Il fait émerger, par ses analyses, le dialogue entre philosophie et poésie, qui a parcouru, de manière conflictuelle, toute notre tradition culturelle. 